\title{
Editorial on ICT and education internationally
}

\author{
Arthur Tatnall
}

Published online: 24 January 2013

(C) Springer Science+Business Media New York 2013

This first issue of EAIT for 2013 has articles from India, USA, Egypt, Cyprus, Spain, Finland and Greece, illustrating the word-wide and growing interest in education and information technologies. From a topic that began in the 1980s as an area of interest in relatively few countries, issues relating to ICT and education are now very much an international phenomenon as this issue illustrates.

Applications of blogging in problem based learning by Rishu Chhabra and Vandana Sharma from Punjab Technical University, India, looks at an undergraduate course on relational database management systems in Computer Science and Engineering. The article describes how problem based learning and blogging have been introduced for practical sessions. It discusses how problems are designed to cover the syllabus topics, and how blogging was used to bridge the communication gap.

Students' perceptions of clickers as an instructional tool to promote active learning, is by James Oigara from Canisius College, and Jared Keengwe from the University of North Dakota, USA. In the article they write to describe a study to evaluate students' perceptions of active learning in a Physical Geography undergraduate class. The study found that clickers do promote student engagement in the teaching and learning process, but that students did not find clickers to be a motivating factor to study more for the course.

An interactive e-learning system for improving web programming skills, by Elgamal, Abas and Baladoh from Mansoura University, Egypt describes an interactive e-learning system that aims to provide an integrated environment for web programming. The system provides instructors with an online exam system and monitors, collects and keeps information about learners' performance and activities.

Locating ICT for primary education in a reformed Greek-Cypriot national curriculum: A documentary analysis approach by Yiasemina Karagiorgi from the Ministry of Education and Culture, Nicosia, Cyprus argues that educational technology in the

\footnotetext{
A. Tatnall $(\bowtie)$

Victoria University, PO Box 14428 Melbourne 8001, Australia

e-mail: Arthur.Tatnall@vu.edu.au
} 
Greek-Cypriot educational system has reached a critical point since ICT now appears for the first time in the newly reformed national curriculum. The reported study illuminates the ways in which ICT is depicted in this curriculum with regard to primary education and also explores whether the approach adopted appears consistent.

E-learning and market orientation in higher education is by Carlos Flavián, Luis Longás and Javier Lozano from the University of Zaragoza, Spain. In the article they argue that technology is modifying the way companies do business all over the world, and the education sector is no different They note that virtual education has emerged as a basic tool to satisfy the changing needs of traditional and newly incorporated students as well as meeting the new requirements of educational institutions. The article analyses what drives the development of online education within the universities of the European Union. It also describes an attempt to design a theoretical framework to obtain responses to question of why students continue their e-studies at the same educational institution.

A triangular prism model: Using activity theory to examine online learning communities, by Jared Keengwe from the University of North Dakota and Jung-Jin Kang from Michigan State University, examines how a triangular prism model could help researchers examine challenging and successful factors to sustaining online learning communities for pre-service and in-service teachers. The triangular prism model is a conceptual framework that guides empirical examination of online learning communities' ongoing development and their connections within a relevant context, and the article highlights the application of this framework to these two online learning communities.

Towards sustainable well-being in SMEs through the web-based learning program of ergonomics, is an article by Marja Randelin (University of Eastern Finland), Terhi Saaranen (Finnish Institute of Occupational Health), Paula Naumanen (University of Oulu) and Veikko Louhevaara (Finland). In their article they note that promoting well-being at work in the context of sustainable development is a complex and dynamic issue and that organizational learning is one requirement. The study they describe aimed to identify and describe characteristics of the learning program to promote sustainable well-being at work, implemented in small and medium-sized enterprises. The results suggest that, in the light of promoting sustainable well-being at work the learning program of ergonomics may be considered an efficient and straightforward distance learning program accessible through the Internet.

The article: Spreadsheets as cognitive tools: A study of the impact of spreadsheets on problem solving of math story problems is by Kostas Lavidas (University of Patras), Vasilis Komis (University of Patras) and Vasilis Gialamas (National and Kapodistrian University of Athens). In the article they investigated the impact of computer spreadsheets on the problem solving practices of students for math problems, and more specifically on the transition from arithmetic to algebraic reasoning through the construction of algebraic expressions. They see verification of solution and reasoning to constitute a critical step in the process of problem solving, and investigated the relationships among the students' prior knowledge and skills, the verification processes, and the effectiveness of the problem solving tasks. 